\title{
Summary Report on the Fuel Performance Modeling of the AFC-2A, 2B Irradiation Experiments
}

Pavel Medvedev

September 2013

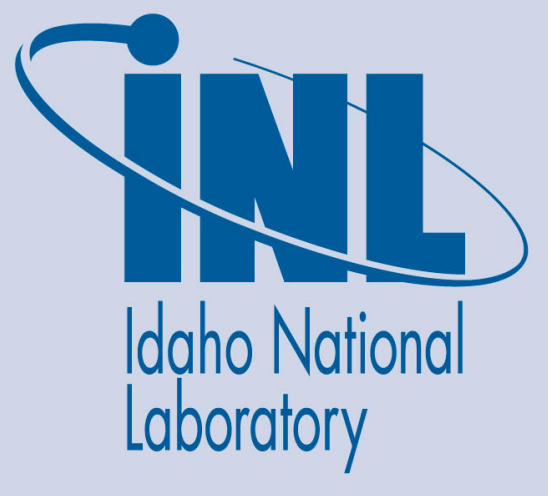

The INL is a U.S. Department of Energy National Laboratory operated by Battelle Energy Alliance 
INL/EXT-13-30006

\title{
Summary Report on the Fuel Performance Modeling of the AFC-2A, 2B Irradiation Experiments
}

\author{
Pavel Medvedev
}

September 2013

\author{
Idaho National Laboratory \\ Fuel Cycle Research \& Development \\ Advanced Fuels Campaign \\ Idaho Falls, Idaho 83415 \\ http://www.inl.qov
}

Prepared for the

U.S. Department of Energy

Office of Nuclear Energy

Under DOE Idaho Operations Office

Contract DE-AC07-05ID14517 


\section{DISCLAIMER}

This information was prepared as an account of work sponsored by an agency of the U.S. Government. Neither the U.S. Government nor any agency thereof, nor any of their employees, makes any warranty, expressed or implied, or assumes any legal liability or responsibility for the accuracy, completeness, or usefulness, of any information, apparatus, product, or process disclosed, or represents that its use would not infringe privately owned rights. References herein to any specific commercial product, process, or service by trade name, trade mark, manufacturer, or otherwise, does not necessarily constitute or imply its endorsement, recommendation, or favoring by the U.S. Government or any agency thereof. The views and opinions of authors expressed herein do not necessarily state or reflect those of the U.S. Government or any agency thereof. 
INTENTIONALLY BLANK 


\section{SUMMARY}

The primary objective of this work at the Idaho National Laboratory (INL) is to determine the fuel and cladding temperature history during irradiation of the AFC-2A, 2B transmutation metallic fuel alloy irradiation experiments containing transuranic and rare earth elements. Addition of the rare earth elements intends to simulate potential fission product carry-over from pyro-metallurgical reprocessing. Post irradiation examination of the AFC-2A, 2B rodlets revealed breaches in the rodlets and fuel melting which was attributed to the release of the fission gas into the helium gap between the rodlet cladding and the capsule which houses six individually encapsulated rodlets. This release is not anticipated during nominal operation of the AFC irradiation vehicle that features a double encapsulated design in which sodium bonded metallic fuel is separated from the ATR coolant by the cladding and the capsule walls. The modeling effort is focused on assessing effects of this unanticipated event on the fuel and cladding temperature with an objective to compare calculated results with the temperature limits of the fuel and the cladding. 
INTENTIONALLY BLANK 


\section{CONTENTS}

SUMMARY $\mathrm{V}$

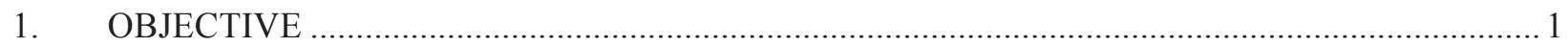

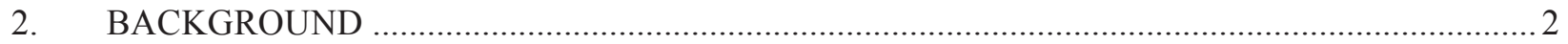

2.1 Description of the BISON Fuel Performance Code ….............................................................2

2.2 AFC-2A, 2B Fuel Irradiation Experiment Design and Operating Conditions .......................2

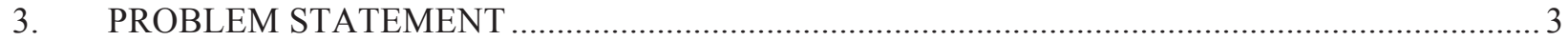

4. FUEL BEHAVIOR MODELS USED IN THE PRESENT STUDY …....................................... 4

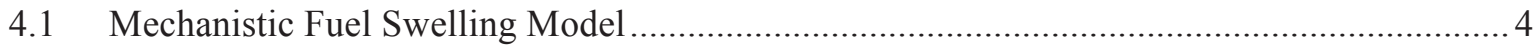

4.1.1 Fuel Swelling Due to Fission Gas and Fission Gas Release ….................................. 4

4.1.2 Fuel Swelling Due to Solid Fission Products ............................................................ 5

4.2 Degradation of the Fuel Thermal Conductivity ............................................................... 5

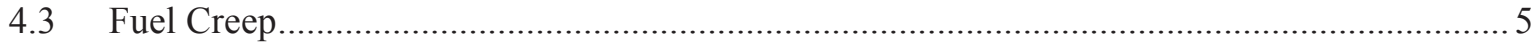

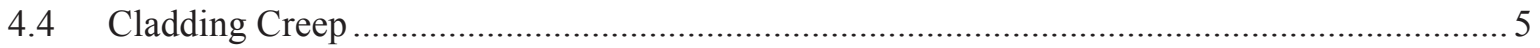

4.5 Coupling Between the Models to Capture the Multiphysics Phenomena ............................6

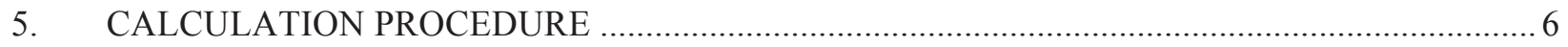

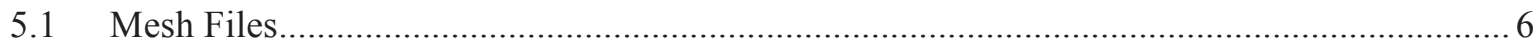

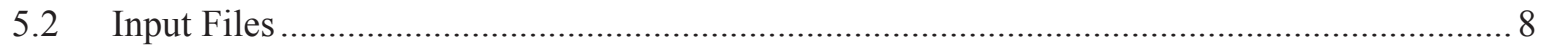

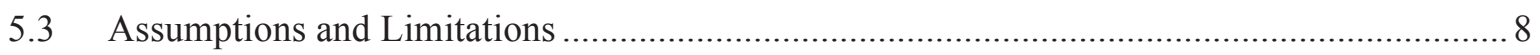

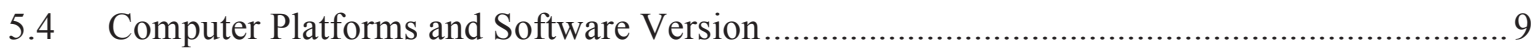

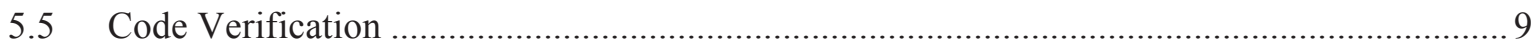

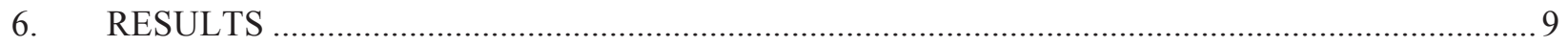

6.1 Peak Fuel and Cladding Temperature History …......................................................... 9

6.1.1 Peak Fuel and Cladding Temperature During Nominal Operation ............................9

6.1.2 Effect of a breach in a single rodlet on the fuel and cladding temperature ............... 10

6.1.3 Effect of simultaneous breaches in multiple rodlets on the fuel and cladding

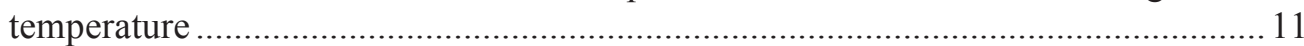




\section{FIGURES}

Figure 1. Post irradiation examination images of AFC-2A (left) and AFC-2B (right) rodlet

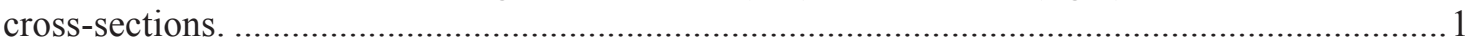

Figure 2. A schematic of the AFC-2A, 2B rodlet assembly (not to scale) …...............................................

Figure 3. A schematic of the AFC-2A, 2B capsule assembly (not to scale). ............................................ 3

Figure 4. Coupling between the models to capture the multiphysics phenomena. ................................... 6

Figure 5. A diagram of the QUAD4 element used in the rodlet assembly mesh. ...................................

Figure 6. Fragment the meshed geometries of the capsule assembly including capsule, cladding

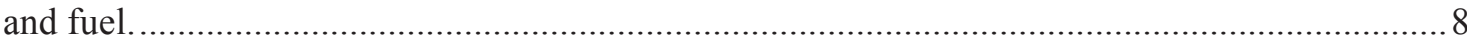

Figure 7. Peak fuel temperature history during the AFC-2A (left) and AFC-2B (right) irradiation assuming nominal operation.

Figure 8. Peak cladding history during the AFC-2A (left) and AFC-2B (right) irradiation assuming nominal operation.

Figure 9. Effect of a breach in rodlet 4 on the fuel temperature during the AFC-2A (left) and AFC-2B (right) irradiation.

Figure 10. Effect of a breach in rodlet 4 on the cladding temperature during the AFC-2A (left) and $\mathrm{AFC}-2 \mathrm{~B}$ (right) irradiation.

Figure 11. Effect of simultaneous breaches in multiple rodlets on the fuel temperature during the AFC-2A (left) and AFC-2B (right) irradiation.

Figure 12. Effect of simultaneous breaches in multiple rodlets on the cladding temperature for the AFC-2A (left) and AFC-2B (right) irradiation.

\section{TABLES}

Table 1. Composition and operating conditions of the AFC-2A irradiation experiment, irradiation time 213.9 days.

Table 2. Composition and operating conditions of the AFC-2B irradiation experiment, irradiation time 363.8 days.

Table 3. Key parameters of the mesh used for the rodlet assembly model. ............................................

Table 4. Rodlet assembly dimensions used to generate metal rodlet mesh files....................................... 7

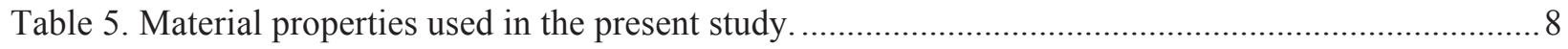




\section{Summary Report on the Fuel Performance Modeling of the AFC-2A, 2B Irradiation Experiments}

\section{OBJECTIVE}

The primary objective of this work at the Idaho National Laboratory (INL) is to determine the fuel and cladding temperature history during irradiation of the AFC-2A, 2B transmutation metallic fuel alloy irradiation experiments containing transuranic and rare earth elements. Addition of the rare earth elements intends to simulate potential fission product carry-over from pyro-metallurgical reprocessing. As shown in Figure 1, post irradiation examination ${ }^{1,2}$ of the AFC-2A, 2B rodlets revealed breaches in the rodlets and fuel melting which was attributed to the release of the fission gas into the helium gap between the rodlet cladding and the capsule which houses six individually encapsulated rodlets. This release is not anticipated during nominal operation of the AFC irradiation vehicle that features a double encapsulated design in which sodium bonded metallic fuel is separated from the ATR coolant by the sealed cladding and the sealed capsule. Therefore, the modeling effort is focused on assessing effects of this unanticipated event on the fuel and cladding temperature with an objective to compare calculated results with the temperature limits of the fuel and the cladding.

This work constitutes a research and development activity that is exploratory, preliminary, or investigative in nature.
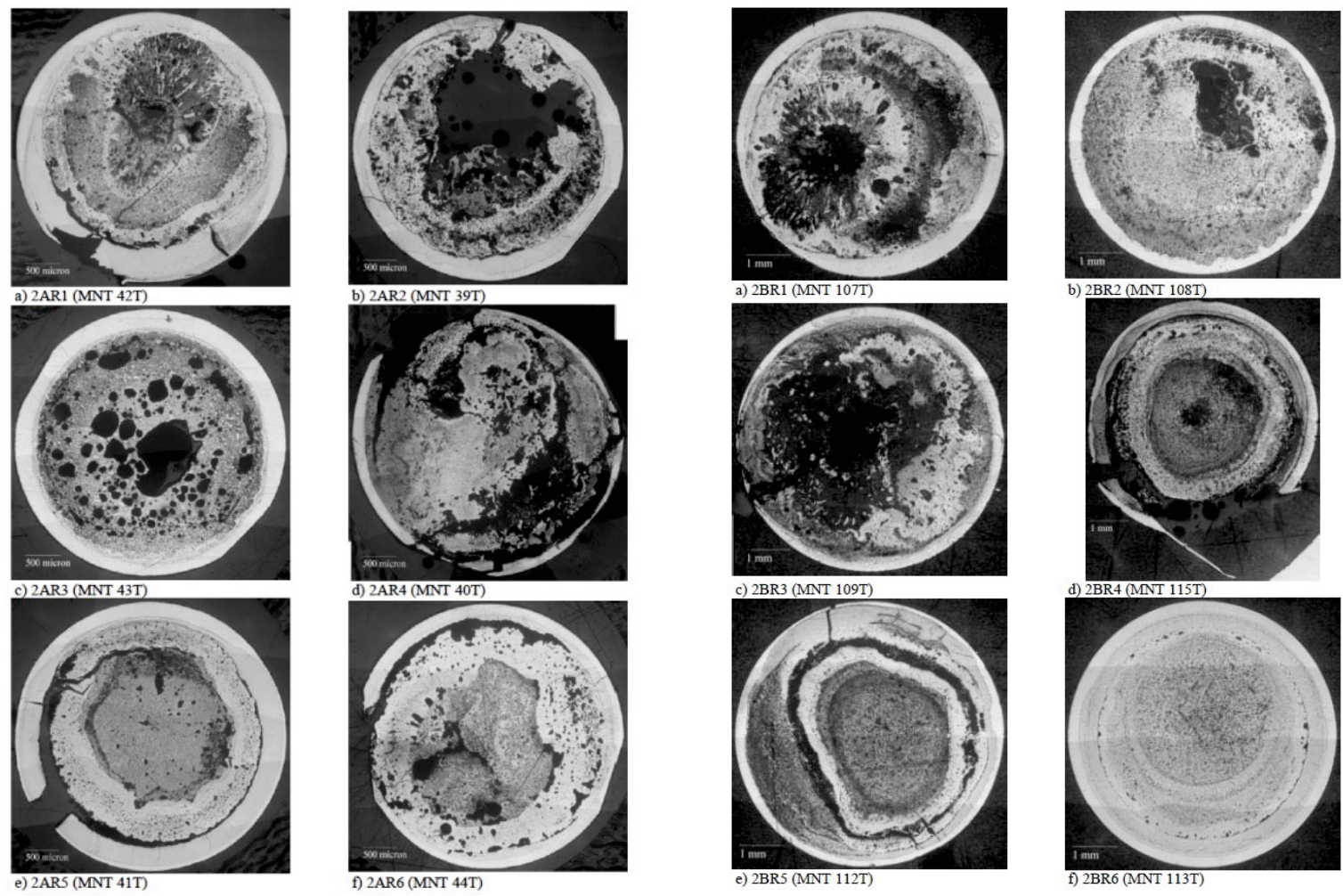

Figure 1. Post irradiation examination images of AFC-2A (left) and AFC-2B (right) rodlet cross-sections. 


\section{BACKGROUND}

\subsection{Description of the BISON Fuel Performance Code}

The fuel performance modeling effort described in the present report was executed using the BISON fuel performance code. $\mathrm{BISON}^{3}$ is a finite element-based engineering scale fuel performance code based on the Multiphysics Object-Oriented Simulation Environment (MOOSE) framework. ${ }^{4}$ BISON solves the fully-coupled thermomechanics and species diffusion equations in two or three dimensional space. The code is currently under development and is being actively advanced by including multiphysics constitutive behavior models, and coupling to lower-length scale material models. Applicable to both steady and transient operation, BISON is designed for efficient use on parallel computers. Current applications include oxide, metal, and tristructural-isotropic (TRISO) nuclear fuels.

\subsection{AFC-2A, 2B Fuel Irradiation Experiment Design and Operating Conditions}

The motivation for the AFC-2A, 2B series experiments is the development of the metallic fuels containing minor actinides for transmutation of the long-lived transuranic actinide isotopes contained in spent nuclear fuel into shorter-lived fission products. Addition of the rare earth elements intends to simulate potential fission product carry-over from pyro-metallurgical reprocessing.

AFC-2A, 2B experiment design and operating conditions are described in detail in the experiment thermal evaluation, ${ }^{5}$ and the as-run and projected physics evaluations. ${ }^{6}$ Design and operating conditions information critical for the execution of the present study are summarized in Table 1 and Table 2. Detailed dimensions of the AFC-2A, 2B rodlet assembly are given in the corresponding engineering drawings. ${ }^{7,8}$ A schematic of the AFC-2A, 2B rodlet assembly is given in Figure 2 and Figure 3.

Table 1. Composition and operating conditions of the AFC-2A irradiation experiment, irradiation time 213.9 days.

\begin{tabular}{|c|l|c|}
\hline Rodlet & \multicolumn{1}{|c|}{ AFC-2A Nominal Composition } & $\begin{array}{c}\text { Average LHGR } \\
(\mathrm{W} / \mathrm{cm})\end{array}$ \\
\hline 1 & U-20Pu-3Am-2Np-15Zr & 315 \\
\hline 2 & U-20Pu-3Am-2Np-1.0RE*-15Zr & 330 \\
\hline 3 & U-20Pu-3Am-2Np-1.5RE*-15Zr & 311 \\
\hline 4 & U-30Pu-5Am-3Np-1.5RE*-20Zr & 319 \\
\hline 5 & U-30Pu-5Am-3Np-1.0RE*-20Zr & 307 \\
\hline 6 & U-30Pu-5Am-3Np-20Zr & 288 \\
\hline
\end{tabular}

Table 2. Composition and operating conditions of the AFC-2B irradiation experiment, irradiation time 363.8 days.

\begin{tabular}{|c|l|c|}
\hline Rodlet & \multicolumn{1}{|c|}{ AFC-2B Nominal Composition } & $\begin{array}{c}\text { Average LHGR } \\
(\mathrm{W} / \mathrm{cm})\end{array}$ \\
\hline 1 & $\mathrm{U}-20 \mathrm{Pu}-3 \mathrm{Am}-2 \mathrm{~Np}-15 \mathrm{Zr}$ & 324 \\
\hline 2 & $\mathrm{U}-20 \mathrm{Pu}-3 \mathrm{Am}-2 \mathrm{~Np}-1.0 \mathrm{RE}^{*}-15 \mathrm{Zr}$ & 332 \\
\hline 3 & $\mathrm{U}-20 \mathrm{Pu}-3 \mathrm{Am}-2 \mathrm{~Np}-1.5 \mathrm{RE}^{*}-15 \mathrm{Zr}$ & 316 \\
\hline 4 & $\mathrm{U}-30 \mathrm{Pu}-5 \mathrm{Am}-3 \mathrm{~Np}-1.5 \mathrm{RE}^{*}-20 \mathrm{Zr}$ & 348 \\
\hline 5 & $\mathrm{U}-30 \mathrm{Pu}-5 \mathrm{Am}-3 \mathrm{~Np}-1.0 \mathrm{RE}^{*}-20 \mathrm{Zr}$ & 313 \\
\hline 6 & $\mathrm{U}-30 \mathrm{Pu}-5 \mathrm{Am}-3 \mathrm{~Np}-20 \mathrm{Zr}$ & 294 \\
\hline
\end{tabular}




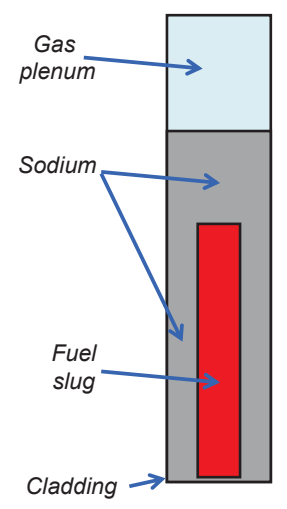

Figure 2. A schematic of the AFC-2A, 2B rodlet assembly (not to scale).

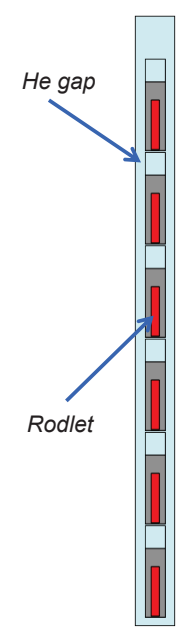

Figure 3. A schematic of the AFC-2A, 2B capsule assembly (not to scale).

\section{PROBLEM STATEMENT}

Given the power history, material properties, and rodlet assembly design determine the fuel and cladding temperature during irradiation of the AFC-2A, 2B irradiation experiments. Consider the case when the fuel and the nominal operation of the irradiation vehicle and the case when one or several rodlets are breached and the contents of the rodlet gas plenum are released into the gap between the rodlet cladding and the capsule. Assess the effects of rodlet breach on the fuel and cladding temperature with an objective to compare calculated results with the temperature limits of the fuel and the cladding. 


\section{FUEL BEHAVIOR MODELS USED IN THE PRESENT STUDY 4.1 Mechanistic Fuel Swelling Model \\ 4.1.1 Fuel Swelling Due to Fission Gas and Fission Gas Release}

To assess the swelling of the annular fuel early in life, a mechanistic fuel swelling model was developed and implemented in the BISON code. The derivation of the swelling model is was described previously.

Assume that the fission gas generated in the fuel instantly forms fission gas bubbles having diameter of $5 \mu \mathrm{m}$. Mechanical force balance on an equilibrium bubble can be expressed as follows.

$\mathrm{p}=\frac{2 \gamma}{\mathrm{r}_{\mathrm{b}}}-\sigma_{\mathrm{h}}+\sigma_{\mathrm{cr}}$

where $p$ is the pressure of the fission gas in a bubble, $\gamma$ surface tension of the fuel, $r_{b}$ is the fission gas bubble size, $\sigma_{h}$ is the hydrostatic stress in the fuel, and $\sigma_{c r}$ is the creep strength stress of the fuel. The gas pressure in the bubble is governed by the ideal gas law:

$\mathrm{pV}=\mathrm{vRT}$

where $p, V, v, R, T$, are pressure, volume, amount, universal gas constant, and temperature of the fission gas, respectively.

Rearranging Equation (2) to calculate volume of the fission gas and substituting Equation (2), obtain the following expression for the volume of the fission gas:

$\mathrm{V}=\frac{\nu \mathrm{RT}}{\frac{2 \gamma}{\mathrm{r}_{\mathrm{b}}}-\sigma_{\mathrm{h}}+\sigma_{\mathrm{cr}}}$.

Amount of the of fission gas generated per unit volume of fuel:

$v=\frac{0.26 \mathrm{~F}}{\mathrm{~N}_{\mathrm{A}}}$

where $F$ is fission density, 0.26 is fission yield of gas atoms, $N_{A}$ is the Avogadro number. Substituting

$$
\begin{aligned}
& \mathrm{r}_{\mathrm{b}}=0.5 \mu \mathrm{m}, \\
& \gamma=0.8 \mathrm{~N} / \mathrm{m}, \text { according to Karahan }{ }^{10}, \\
& \sigma_{\mathrm{cr}}=6.9 \times 10^{6} \mathrm{~Pa}, \text { from Churchman }{ }^{11} \text { for pure } \mathrm{U},
\end{aligned}
$$

obtain fuel swelling due to fission gas:

$\left(\frac{\Delta \mathrm{V}}{\mathrm{V}_{0}}\right)_{\mathrm{g}}=\frac{3.59 \times 10^{-24} \mathrm{FT}}{1.01 \times 10^{7}-\sigma_{\mathrm{h}}}$,

where $T$ is in degrees Kelvin, $F$ is in fissions $/ \mathrm{m}^{3}, \sigma_{\mathrm{h}}$ is in $\mathrm{Pa}$.

According to Barnes, ${ }^{12}$ when swelling due to fission gas bubbles reaches $33 \%$, the fission gas bubbles interconnect, and the fission gas is released. Interconnection of the fission gas bubbles transforms closed porosity into the open porosity that facilitates instant release of any consequently generated fission gas. Thus, the fission gas induced swelling is terminated, once the interconnection threshold is reached. These phenomena were implemented in the code by limiting maximum attainable fission gas induced swelling to $33 \%$, and setting fission gas release value to $80 \%$, once the interconnection threshold is reached. The latter value is based on the assumption that $20 \%$ of the fission gas is retained in isolated bubbles once the rest of the bubbles interconnect. This methodology is expressed as follows: 
if $\left(\frac{\Delta V}{V_{0}}\right)_{g}>0.33, F G R=80 \%$

\subsubsection{Fuel Swelling Due to Solid Fission Products}

Swelling due to solid fission products is assumed to be $1.5 \%$ per $1 \%$ burnup. Noting that

$B u(\%)=\frac{F}{N_{h m 0}} 100$,

where $N_{h m o}$ is initial number of heavy metal atoms in the fuel and $F$ is fission density, the swelling due to solid fission products expressed in terms of the fission density is

$\left(\frac{\Delta V}{V_{0}}\right)_{S}=0.015 B u(\%)=0.015 \frac{F}{N_{h m 0}} 100=0.015 \frac{F}{3.6 \times 10^{28}} 100=4.16 \times 10^{-29} \mathrm{~F}$.

\subsection{Degradation of the Fuel Thermal Conductivity}

To account for degradation of thermal conductivity due to the fission gas induced porosity, a methodology developed by Billone ${ }^{12}$ was adopted. Equations (9) and (10) were used for the fuel alloys containing $15 \% \mathrm{Zr}$ and $20 \% \mathrm{Pu}$ and $20 \% \mathrm{Zr}$ and $30 \% \mathrm{Pu}$ respectively.

$k=\left(4.3148 \times 10^{-6} T^{2}+1.5289849 \times 10^{-2} T+0.210789368\right) \frac{1-p}{1+2.5 p}$,

$k=\left(1.7822 \times 10^{-6} T^{2}+1.594913 \times 10^{-2} T-6.42141452\right) \frac{1-p}{1+2.5 p}$,

where $T$ is temperature in $\mathrm{K}$, and $p$ is fuel porosity. Fuel porosity is calculated using fission gas induced swelling:

$p=\frac{\left(\frac{\Delta V}{V_{0}}\right)_{g}}{\left(\frac{\Delta V}{V_{0}}\right)_{g}+1}$,

\subsection{Fuel Creep}

Fuel creep rate is temperature, stress, porosity, and fission rate dependent and is calculated using published methodology. ${ }^{13}$

$\varepsilon^{\prime}=5000 \times\left(1+7.9 p+470 p^{2}\right) \sigma \exp \left(-\frac{52000}{R T}\right)+$

$+6\left(1-p^{0.67}\right)^{-0.8} \sigma^{4.5} \exp \left(\left(-\frac{52000}{R T}\right)+7.7 \times 10^{-23} \sigma F^{\prime}\right.$,

where $p, \sigma, R, T, F$ ' are porosity, stress, gas constant, temperature, and fission rate respectively.

\subsection{Cladding Creep}

Cladding creep rate is temperature and stress dependent and is calculated using published methodology. ${ }^{14}$

$\varepsilon^{\prime}=1.17 \times 10^{9} \sigma^{2} \exp \left(-\frac{83142}{1.987 T}\right)+8.33 \times 10^{9} \sigma^{5} \exp \left(-\frac{108276}{1.987 T}\right)$

where $\sigma$, and $T$, are stress and temperature respectively. 


\subsection{Coupling Between the Models to Capture the Multiphysics Phenomena}

Examination of equations presented above reveals complex interdependence of fuel performance parameters and behavior models. To capture this interdependence, the equations were coupled in a manner depicted in Figure 4, utilizing BISON's advanced object oriented architecture, and producing a truly multiphysical model of the metallic fuel swelling and deformation. The implementation of the model was carried out by the present study specifically to address FCRD metallic fuel development challenges. By accounting for the effects of FCMI and temperature on swelling, and by using extensive coupling, the present model constitutes a significant advancement of the generic version of the BISON code distributed to users.

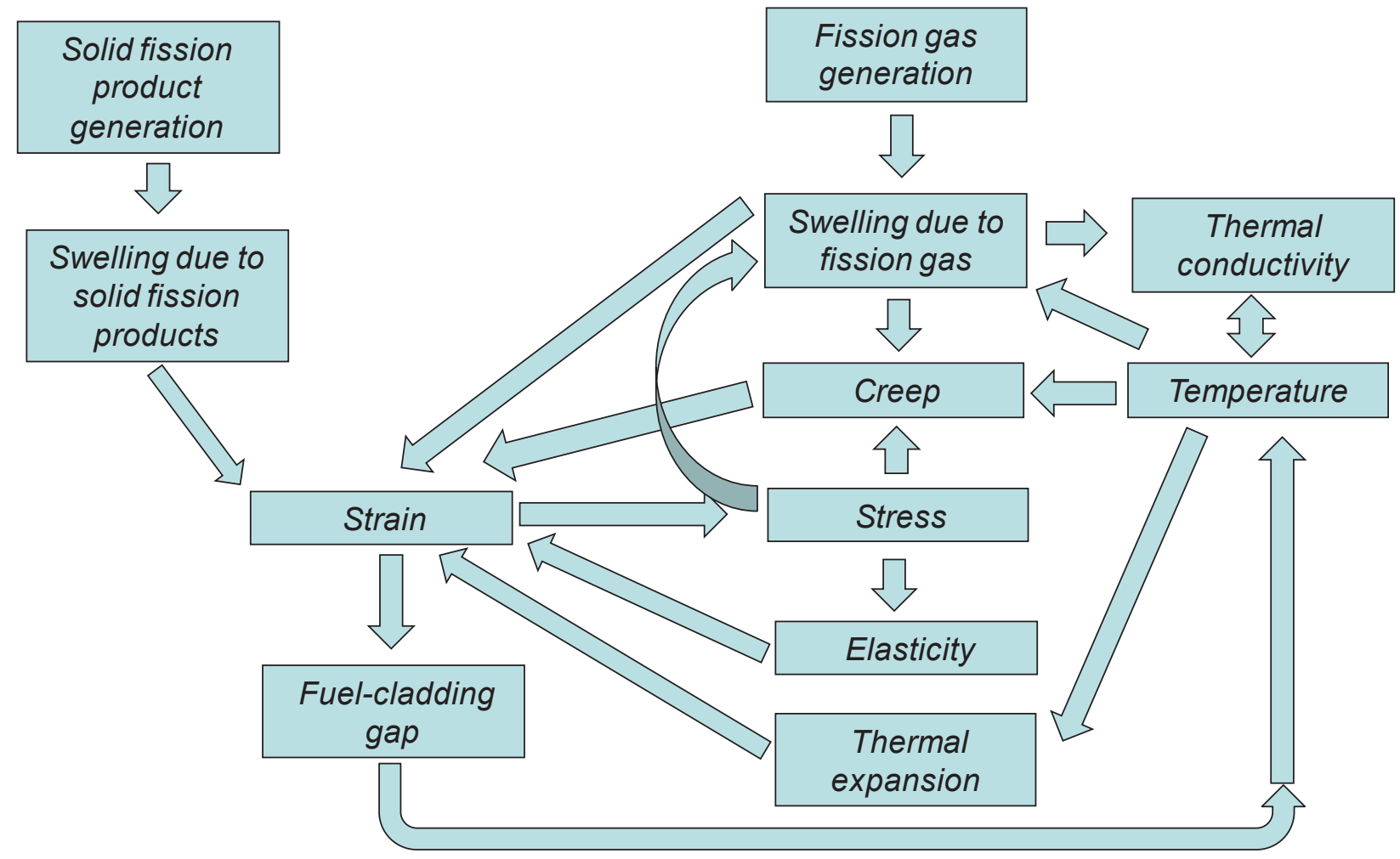

Figure 4. Coupling between the models to capture the multiphysics phenomena.

\section{CALCULATION PROCEDURE}

Execution of the fuel performance calculation using BISON requires two problem-specific files: (1) a mesh file that contains description of the problem geometry, and (2) an input file that includes information on material properties, power history, boundary conditions and parameters that control numerical algorithms in BISON.

\subsection{Mesh Files}

Mesh files were created using CUBIT Version 13.1 geometry and mesh generation toolkit. ${ }^{15}$ The mesh consisted of eight blocks: six fuel slugs, six cladding tubes, and one capsule. Establishing eight blocks in a mesh allows assigning specific material properties to each block. Heat generation rate is assigned to the fuel blocks. The key parameters of the mesh are given in Table 3. A two-dimensional axisymmetric mesh was utilized to reduce the computational size of the problem by a factor of two. The fragment of the resulting mesh is shown in Figure 6. 
Table 3. Key parameters of the mesh used for the rodlet assembly model.

\begin{tabular}{|c|l|c|c|}
\hline Block & \multicolumn{1}{|c|}{ Component } & $\begin{array}{c}\text { Number of } \\
\text { elements }\end{array}$ & Element type \\
\hline $1-6$ & Fuel & 704 & QUAD4 \\
\hline 7 & Cladding & 4448 & QUAD4 \\
\hline 8 & Capsule & 3992 & QUAD4 \\
\hline
\end{tabular}

An image of the QUAD4 used in the model element is shown in Figure 5. This is a linear order element featuring four nodes located in the corners.

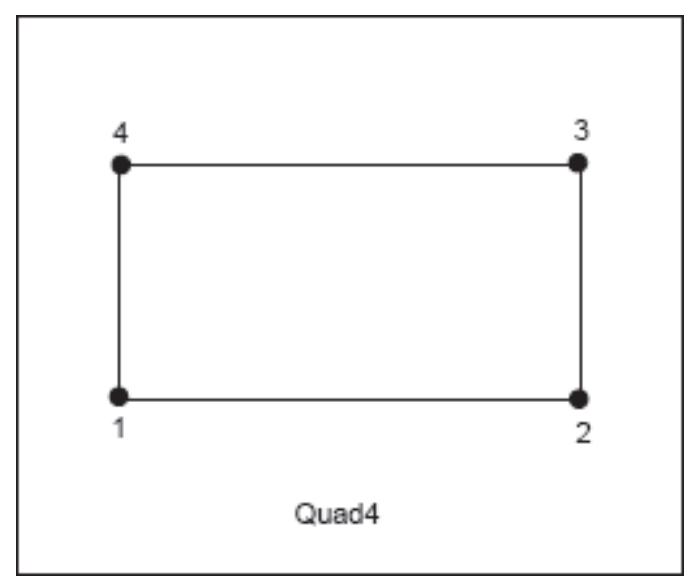

Figure 5. A diagram of the QUAD4 element used in the rodlet assembly mesh.

Rodlet assembly dimensions used to generate metal rodlet mesh files are listed in Table 4.

Table 4. Rodlet assembly dimensions used to generate metal rodlet mesh files.

\begin{tabular}{|l|c|}
\hline Fuel diameter, mm & 4.470 \\
\hline Fuel length, mm & 38.100 \\
\hline Fuel-cladding radial gap, mm & 0.229 \\
\hline Cladding wall thickness, mm & 0.457 \\
\hline Capsule outer diameter, mm & 8.992 \\
\hline Capsule inner diameter, $\mathrm{mm}$ & 5.944 \\
\hline
\end{tabular}

The image of a fragment the meshed geometries of the capsule assembly, capsule, cladding and fuel is shown in Figure 6. The fuel/cladding and cladding/capsule gaps were not meshed. Instead, temperature drops across these gaps were calculated from the thermal conductivity of the gap material and the heat flux. 


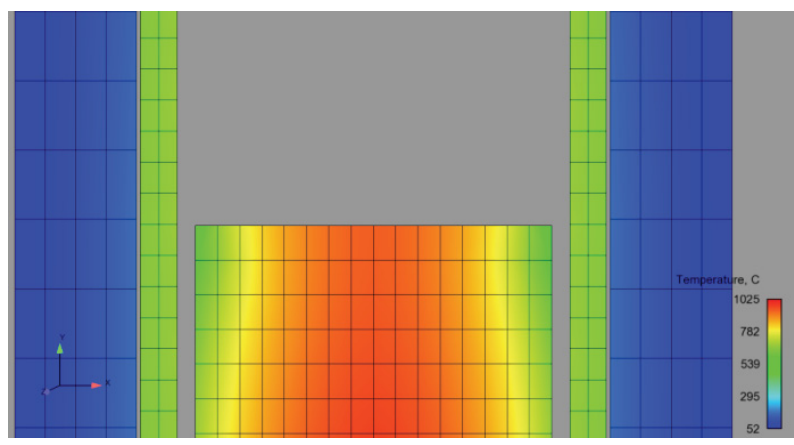

Figure 6. Fragment the meshed geometries of the capsule assembly including capsule, cladding and fuel.

\subsection{Input Files}

Six input files and one mesh files were developed to meet the objectives of the present study. The rodlet breaches was prescribed in the input files by unifying the plenum volumes of breached rodlets with the capcule void volume. The list of material properties used in this study is given in Table 5.

Table 5. Material properties used in the present study.

\begin{tabular}{|l|l|l|l|}
\hline \multicolumn{1}{|c|}{ Material Property } & \multicolumn{1}{|c|}{ Fuel } & \multicolumn{1}{c|}{ Cladding } & \multicolumn{1}{c|}{ Capsule } \\
\hline $\begin{array}{l}\text { Thermal Conductivity } \\
(\mathrm{W} / \mathrm{m}-\mathrm{K})\end{array}$ & $\begin{array}{l}\text { Thermal U30Pu20Zr.C } \\
\text { Thermal U20Pu15Zr.C }\end{array}$ & ThermalHT9.C & 15 \\
\hline Creep & CreepUPuZr.C & ThermalIrradiattionCreepHT9.C & N/A \\
\hline Swelling & VSwellingUPuZr.C & N/A & N/A \\
\hline Young's modulus $(\mathrm{Pa})$ & $7.5 \mathrm{e} 10$ & $1.88 \mathrm{e} 11$ & $1.88 \mathrm{e} 11$ \\
\hline Thermal Expansion $(1 / \mathrm{K})$ & $1.8 \mathrm{e}-5$ & $1.2062 \mathrm{e}-5$ & $1.6180 \mathrm{E}-5$ \\
\hline Poisson Ratio & 0.3 & 0.3 & 0.3 \\
\hline
\end{tabular}

A convective heat flux boundary condition was applied to the surface of the capsule. The coolant temperature of $325 \mathrm{~K}$ and the film coefficient of $40870 \mathrm{~W} / \mathrm{m}^{2}-\mathrm{K}$ were used.

\subsection{Assumptions and Limitations}

Assumptions were required to accomplish the objective with the effort and time allotted for this work. The major assumption and limitations are as follows:

- Frictionless contact between the fuel and the cladding.

- Fuel cladding chemical interaction is not modeled.

- Constituent redistribution in the fuel is not modeled.

- Power generation in an individual fuel slug was assumed uniform.

- The experiment basket is not included in the model.

- $\quad 80 \%$ fission gas release is assumed after gas-induced swelling exceeds $33 \%$.

- Creep of the fuel and cladding was only modeled for the nominal operating conditions of the rodlets. High operating temperatures predicted during non-nominal operation rendered the known creep equations inapplicable. 


\subsection{Computer Platforms and Software Version}

BISON is designed to run on a variety of UNIX and Mac-based computer platforms. All the simulations described in this study were run on a MacPro workstation (model name: Mac Pro; model identifier: MacPro 5.1; operating system: Mac OS X 10.6.7; processor name: 6-Core Intel Xeon; processor speed: $2.93 \mathrm{GHz}$; number of processors: 2; total number of cores: 12), typically using four cores. In all cases, the parallel nature of the calculation is handled completely by the software, with the user simply specifying the number of processors at execution time.

All simulations described in this report were run using BISON at revision number 19012. BISON version control is performed by the Fuel Modeling and Simulation Department of the INL.

\subsection{Code Verification}

Verification tests for the kernels/operators used in this work were successfully executed after the code was compiled. This implies that the agreement was confirmed between the numerical solution produced by BISON and an analytical solution for each verification test. BISON verification tests are developed, maintained, and archived by the Fuel Modeling and Simulation Department of the INL. ${ }^{16}$ Full verification and validation of BISON has not occurred because the code is in a development stage.

\section{RESULTS}

\subsection{Peak Fuel and Cladding Temperature History \\ 6.1.1 Peak Fuel and Cladding Temperature During Nominal Operation}

Peak fuel and cladding temperatures during nominal operation calculated for each rodlet are shown in Figure 7 and Figure 8. The temperatures calculated assuming nominal operating conditions appear to be consistent with the experiment design ${ }^{17}$. Rapid temperature rise observed from the beginning of irradiation is explained by the swelling of the fuel and formation of the fission gas bubbles which results in the reduction of the fuel thermal conductivity as prescribed by the Equations 9 and 10. The temperature difference between different rodlets is due to the difference in operating power (Table 1 and Table 2) and dependence of the fuel thermal conductivity on the fuel composition (Equations 9 and 10). The fuel temperature continues to rise with burnup until the fission gas bubbles interconnect. Bubble interconnection leads to the release of the retained and newly generated fission gas. The microstructure of the fuel that has undergone bubble interconnection is transformed so that the fuel can no longer retain fission gas. After that the fuel swelling continues only due to solid fission product generation, while newly generated fission gas is released directly into the plenum without forming fission gas bubbles. Cessation of the new fission gas bubble formation results in the notable reduction of the fuel swelling rate and stabilization of the fuel thermal conductivity and temperature, as evident from Figure 7 and Figure 8. Slight reduction of the fuel temperature is explained by continuing axial growth of the fuel resulting in the reduction of the linear heat generation rate.

Based on the results shown in Figure 7 and Figure 8, rodlet 4 is clearly identified as the rodlet that would have reached the highest temperature during nominal operation. Based on this observation, to assess the effect of a single rodlet breach on the fuel temperature, it was assumed that rodlet 4 was the first to be breached during irradiation. 

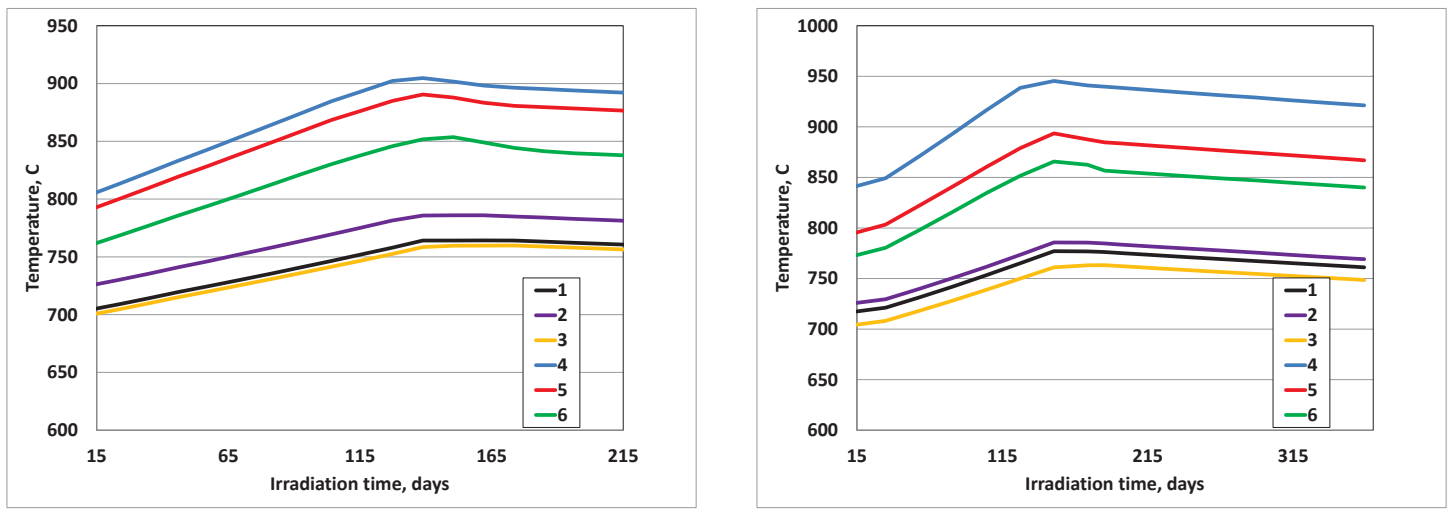

Figure 7. Peak fuel temperature history during the AFC-2A (left) and AFC-2B (right) irradiation assuming nominal operation.
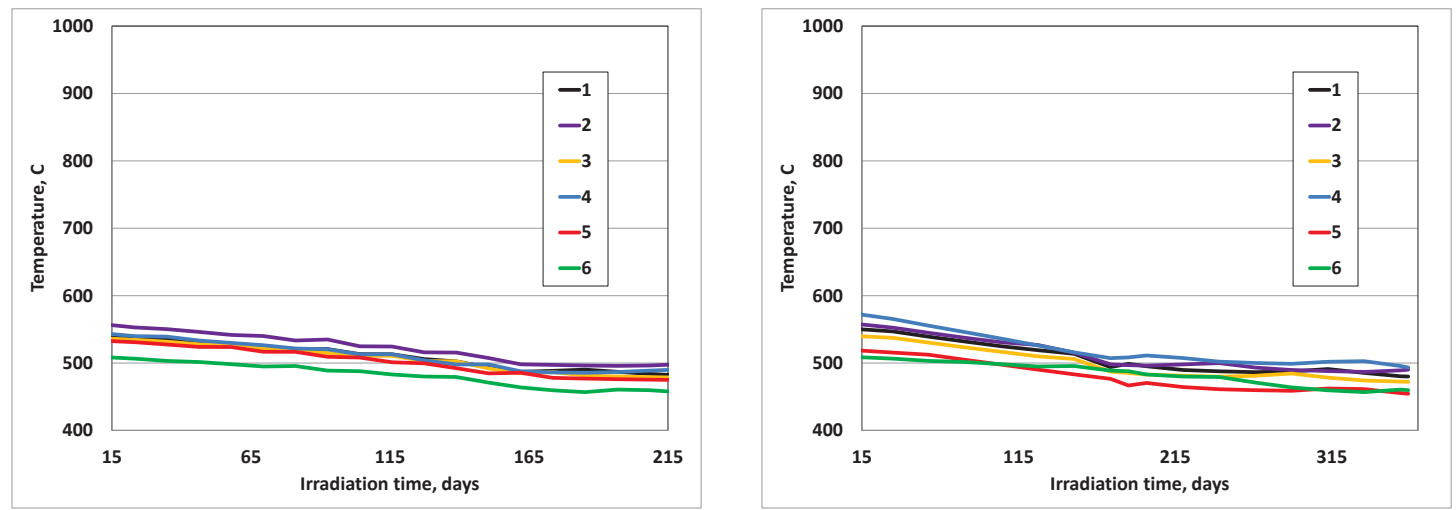

Figure 8. Peak cladding history during the AFC-2A (left) and AFC-2B (right) irradiation assuming nominal operation.

\subsubsection{Effect of a breach in a single rodlet on the fuel and cladding temperature}

Peak fuel and cladding temperatures during operation with breached rodlet 4 calculated for each rodlet are shown in Figure 9 and Figure 10. Fuel and cladding temperatures for the hottest and coldest rodlets during nominal operation are also shown for comparison. It was assumed that the rodlet 4 is breached from the beginning of irradiation, resulting in the instantaneous mixing of the rodlet 4 plenum gas and the capsule fill gas. Because the rodlets were filled with argon-helium mixture, a breach in rodlet 4 in the beginning of irradiation would immediately cause an increase in the fuel and cladding temperature in all rodlets due to contamination of the capsule fill gas (helium) with argon escaping from rodlet 4 . The temperature increase is because the thermal conductivity of argon is significantly lower than the thermal conductivity of helium. The temperature increase associated with argon release from rodlet 4 into the capsule void space during first 115 days of irradiation is evident in Figure 9 and Figure 10 when comparing with nominal temperatures shown as dashed lines and constitutes approximately $40^{\circ} \mathrm{C}$.

The most drastic impact of the breach on the fuel and cladding temperature is predicted when the fission gas porosity in rodlet 4 interconnects and the fission gas release begins. As the fission gas escaping from rodlet 4 contaminates capsule fill gas, the cladding-capsule gap conductance decreases resulting in an increase of the fuel and cladding temperature. It is noted, that soon after the onset of the fission gas release, the cladding temperature reaches and exceeds the design limit ${ }^{17}$ of $650^{\circ} \mathrm{C}$. By the end of irradiation the cladding temperature in most of the rodlets exceeds the temperature of the $\mathrm{Fe}-\mathrm{U}$ eutectic ${ }^{18}$ of $720^{\circ} \mathrm{C}$. Based on this funding it is concluded that the amount of the fission gas released into a 
capsule during a breach of a single rodlet is sufficient to cause an increase in the cladding temperature in the remaining rodlets beyond the design limit and cause their breaches.

Depending on the rodlet, the maximum fuel temperature for the AFC-2A experiment varies from $957^{\circ} \mathrm{C}$ to $1070^{\circ} \mathrm{C}$ and for the $\mathrm{AFC}-2 \mathrm{~B}$ experiment the maximum fuel temperature varies from $1020^{\circ} \mathrm{C}$ to $1160^{\circ} \mathrm{C}$ assuming a single rodlet breach.
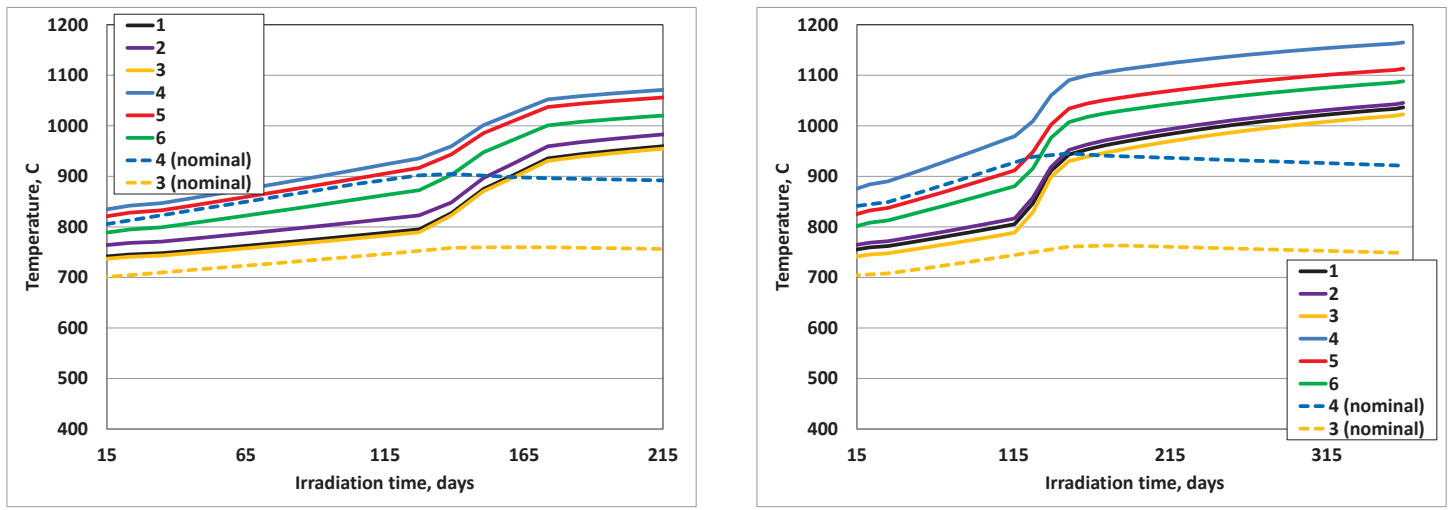

Figure 9. Effect of a breach in rodlet 4 on the fuel temperature during the AFC-2A (left) and AFC-2B (right) irradiation.
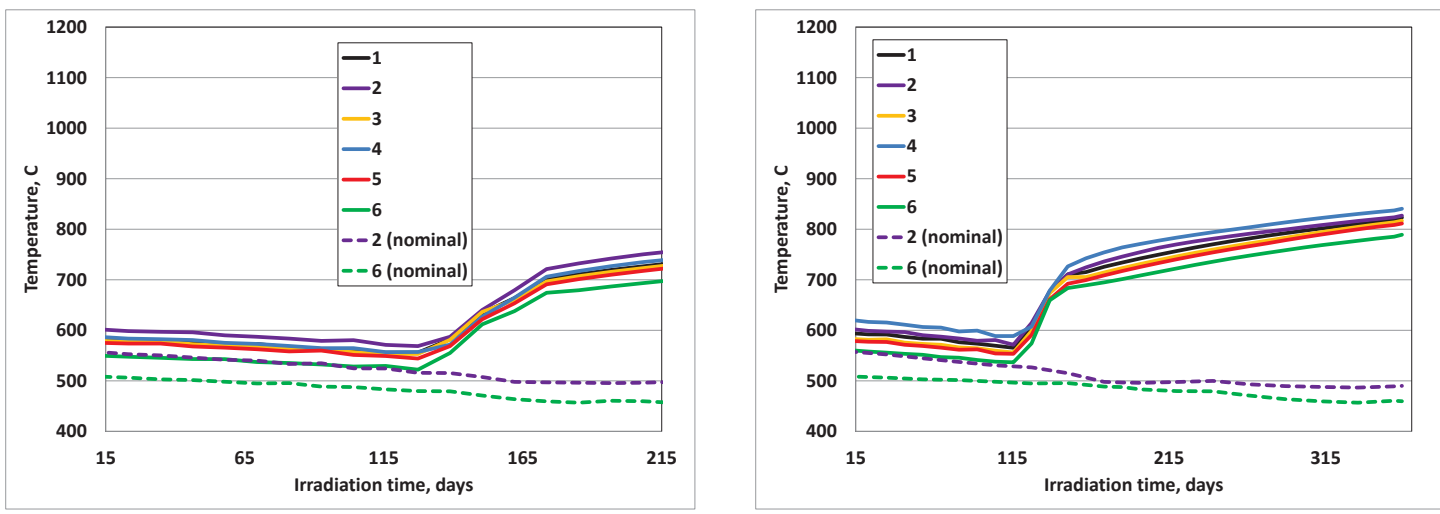

Figure 10. Effect of a breach in rodlet 4 on the cladding temperature during the AFC-2A (left) and AFC-2B (right) irradiation.

\subsubsection{Effect of simultaneous breaches in multiple rodlets on the fuel and cladding temperature}

Because post-irradiation examination results 1'2 indicate breaches in multiple rodlets, in order to determine actual temperatures during irradiation a simulation based on the assumption of breach in five rodlets $(1,2,4,5,6)$ during AFC-2A irradiation, and all six rodlets during AFC-2B irradiation was performed. Effect of simultaneous breaches in multiple rodlets on the fuel and cladding temperature is illustrated in Figure 11 and Figure 12.

The general fuel and cladding temperature trend appears consistent with the one observed in the simulation assuming a single breached rodlet. However, because the amount of fission gas and argon fill gas release into the capsule is 5-6 times greater, the fuel and cladding temperature increases are a lot more pronounced with peak cladding temperatures ranging from $928^{\circ} \mathrm{C}$ to $983^{\circ} \mathrm{C}$ (AFC-2A), and from $1000^{\circ} \mathrm{C}$ to $1040^{\circ} \mathrm{C}(\mathrm{AFC}-2 \mathrm{~B})$, and with peak fuel temperatures ranging from $1144^{\circ} \mathrm{C}$ to $1235^{\circ} \mathrm{C}(\mathrm{AFC}-2 \mathrm{~A})$, and from $1201^{\circ}$ to $1286^{\circ}$ (AFC-2B). 

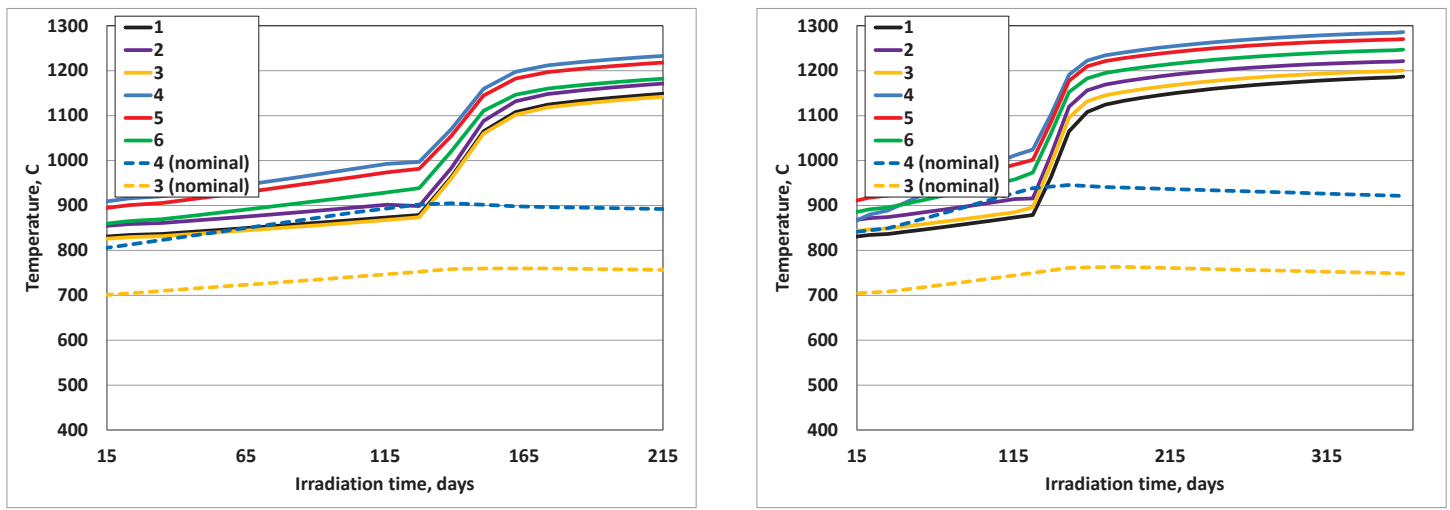

Figure 11. Effect of simultaneous breaches in multiple rodlets on the fuel temperature during the AFC-2A (left) and AFC-2B (right) irradiation.
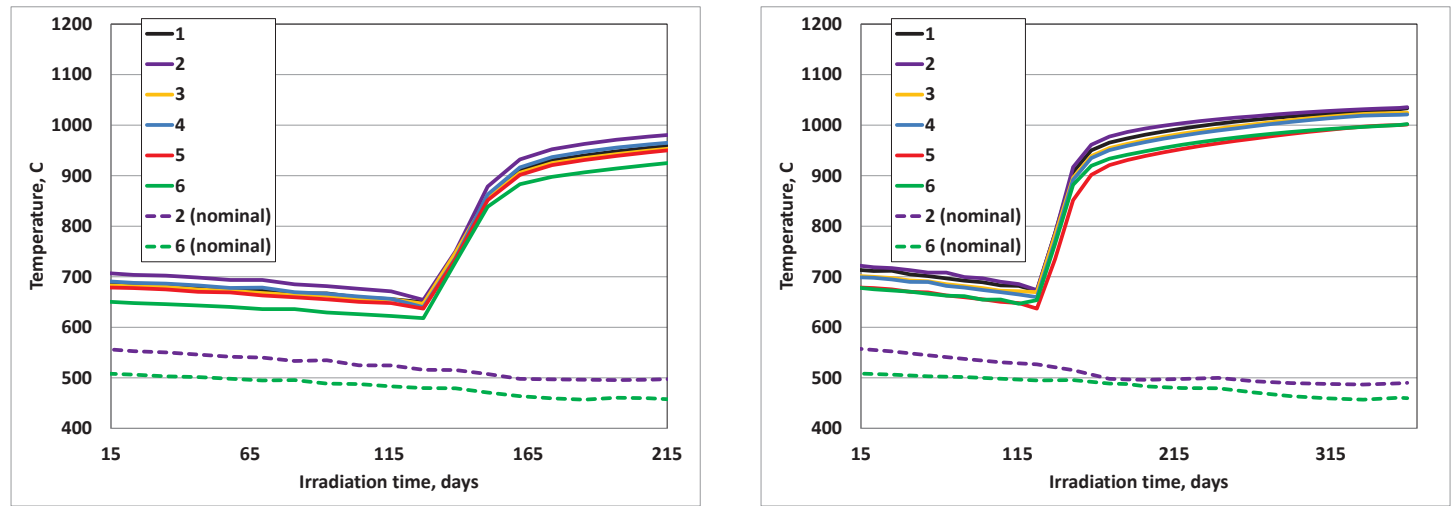

Figure 12. Effect of simultaneous breaches in multiple rodlets on the cladding temperature for the AFC-2A (left) and AFC-2B (right) irradiation.

\section{CONCLUSIONS}

The primary objective of this work at the Idaho National Laboratory (INL) is to determine the fuel and cladding temperature history during irradiation of the AFC-2A, 2B transmutation metallic fuel alloy irradiation experiments. As a result of this study, performance of six double-encapsulated AFC-2A and AFC-2B experiments during irradiation was investigated.

It was found that during nominal operation the fuel and cladding temperatures remained within the experiments design limits. Rodlet 4 was found to have operated at the greatest temperature; therefore, it was assumed that it was the first one to breach.

Irradiation simulation assuming single breached rodlet demonstrated that cladding temperature rise due to breach in a single rodlet is sufficient to cause breaches in remaining rodlets.

Irradiation simulation assuming multiple breached rodlets provided an estimate of the actual fuel and cladding temperatures. It was determined that as a result of the temperature increase associated with the fission gas release from breached rodlets into the capsule the cladding temperatures ranged from $928^{\circ} \mathrm{C}$ to $983^{\circ} \mathrm{C}$ (AFC-2A), and from $1000^{\circ} \mathrm{C}$ to $1040^{\circ} \mathrm{C}$ (AFC-2B), and with peak fuel temperatures ranged from $1144^{\circ} \mathrm{C}$ to $1235^{\circ} \mathrm{C}$ (AFC-2A), and from $1201^{\circ} \mathrm{C}$ to $1286^{\circ} \mathrm{C}(\mathrm{AFC}-2 \mathrm{~B})$. 


\section{REFERENCES}

1. Heather J. MacLean Chichester, Douglas L. Porter, Bruce A. Hilton, Postirradiation Examination of AFC-1D, 1G, 1H, and 2A Experiments, INL/LTD-11-23242, 2011.

2. Heather J. MacLean Chichester, Douglas L. Porter Postirradiation Examination of AFC-2B and AFC-2C Experiments, INL/LTD-12-26154, Idaho National Laboratory, 2012.

3. Williamson, R. L. et al., "Multidimensional multiphysics simulation of nuclear fuel behavior," Journal of Nuclear Materials, 423 (2012) 149-163.

4. Gaston, D., "MOOSE: A parallel computational framework for coupled systems of nonlinear equations," Nuclear Engineering and Design 239 (2009) 1768-1778.

5. Hawkes, G., Thermal Analysis for AFC-2A and AFC-2B Metallic Fuel Experiments, EDF-7808, Idaho National Laboratory, 2010.

6. Lillo M.A., Chang G. S., Cycle 146A Physics Evaluation of the AFC-2B Experiment in the East Flux Trap, ECAR-385, Idaho National Laboratory, 2008.

7. Modified AFC-2 Metallic Fuel Rodlet Assembly, Idaho National Laboratory Engineering Drawing 751074, 2009.

8. Modified AFC-2 Capsule Assembly, National Laboratory Engineering Drawing 751350, 2007.

9. Medvedev P. G., Fuel Performance Modeling Results for Representative FCRD Irradiation Experiments: Projected Deformation in the Annular AFC-3A U-10Zr Fuel Pins and Comparison to Alternative Designs, INL/EXT-12-27183, Idaho National Laboratory, 2012.

10. Karahan A., Modeling of Thermo Mechanical and Irradiation Behavior of Metallic and Oxide Fuels for Sodium Fast Reactors, Thesis, Massachusetts Institute of Technology 2009.

11. Churchman A. T. et al., Effects of Heat and Pressure on the Swelling of Irradiated Uranium, Nuclear Energy, 7 (1958) 8896.

12. Barnes R. S., A Theory of Swelling and Gas Release for Reactor Materials, Journal of Nuclear Materials, 11 (1964) 135148.

13. Kutty T. R. G. et al., Creep behaviour of d phase of U-Zr system by impression creep technique, Journal of Nuclear Materials 408 (2011) 90-95.

14. Crawford et al., AFCI Fuel Irradiation Test Plan, Test Specimens AFC-1Æ and AFC-1F, INEEL/EXT-03-01362, 2003.

15. http://cubit.sandia.gov

16. Idaho National Laboratory internal link https://hpcsc/data/trac/FPCP/browser 
17 .S. L. Hayes, Irradiation of Metallic Fuels with Rare Earth Additions for Actinide Transmutation in the Advanced Test Reactor, INL/EXT-06-11707, Idaho National Laboratory, 2007.

18. Hofman G.L., Walters L.C., Bauer T.H., Metallic fast reactor fuels, Progress in Nuclear Energy, Volume 31, Issues 1-2, 1997, Pages 83-110. 